Finisterra, XXXVII, 74, 2002, pp. 177-180

\title{
PROCESSOS DE REESTRUTURAÇÃO INDUSTRIAL E DESEMPREGO - IMPLICAÇÕES GEOGRÁFICAS
}

PEdRo SOARES ${ }^{1}$

As abordagens que prevaleceram na geografia industrial até aos finais da década de 70 consideravam grosso modo que os padrões locativos eram o resultado de formas de organização e de decisão prévia e objectivamente definidas. As interacções entre economia, geografia e sociedade estiveram ausentes nos trabalhos sobre localização industrial, desde o modelo de localização industrial de A. Weber até às novas perspectivas pós-estruturalistas. Foram as mutações ocorridas a partir da década de 80 que conduziram à necessidade de uma abordagem teórica alternativa que integrasse no território a complexidade intrínseca às relações de produção. De facto, nos anos 80 surgiram novas correntes teóricas, estimuladas pelas alterações verificadas nos padrões de localização industrial e na própria organização da produção, mas também pela evolução que ocorreu nas várias áreas da filosofia e das ciências sociais.

A teoria da estruturação de Anthony Giddens, fundada na crítica à sociologia estruturalista, reconstruiu para a análise dos fenómenos a importância dos conceitos de estrutura e agência em interligação. Giddens reconheceu a dualidade da estrutura - que condiciona o comportamento, o qual, potencialmente, pode influenciar e reconstruir a estrutura -, e a dualidade entre estrutura e agência, que supera as visões determinísticas de estrutura e as voluntaristas de agência.

Tal como Giddens, também o realismo, relançado por Roy Bhaskar nos anos 70, as teorias da regulação divulgadas pela Escola da Regulação Francesa, por Alan Lipietz e outros, e as diversas correntes pós-modernistas, conduziram, cada uma pelo seu próprio caminho teórico, à revalorização do espaço, conferindo papel activo e integrador às formações territoriais. Conforme refere Doreen Massey, não basta olhar para um fenómeno geográfico segundo uma perspectiva bidimensional, ou seja, conceptualizá-lo, em termos do seu padrão, tal como uma superfície que contém apenas distâncias, por onde se distribuem valores de uma ou de diversas variáveis. A mesma autora adianta, para o caso da geografia do emprego, que as estruturas sociais e o processo social consti-

1 Assistente da Faculdade de Letras, Universidade de Lisboa. Investigador do Centro de Estudos Geográficos. E-mail : pedrosoares@mail.doc.fl.ul.pt 
tuem elementos de partida para uma conceptualização do fenómeno, podendo a distribuição espacial do emprego ser interpretada como resultado da forma pela qual a produção se organiza em determinada área geográfica. Deste modo, para a geografia que trata da problemática do emprego, o conceito de relações sociais de produção não poderá deixar de ser chave, entendido no ponto de vista das condições sociais em que opera o processo de produção, tais como a composição do capital, a organização da produção ou as relações entre empregadores e empregados, constituindo o princípio essencial de um modo de produção.

As diferenças que se verificam entre regiões, nomeadamente se uma região acolhe a fase de investigação e desenvolvimento (I\&D) de uma determinada empresa, enquanto que outra apenas capta a fase de montagem do produto, reflectem aspectos das relações sociais de produção ao nível da organização geográfica, com claras repercussões na diferenciação da qualidade do emprego e nas respectivas regiões em geral. É, precisamente, na relação entre, por um lado, produção e classe social e, por outro, organização espacial que procuramos evitar a mera perspectiva bidimensional dos fenómenos, procedendo à sua análise a partir do conceito de estruturas sócio-produtivas regionais. Trata-se, portanto, de encontrar os mecanismos que, considerando o espaço como um elemento activo, integrem as relações sociais de produção na análise da problemática do emprego, sobretudo na vertente que se reporta à perda de postos de trabalho.

Também os fenómenos relacionados com o movimento de internacionalização e globalização das economias trouxeram novas complexidades à análise dos problemas do emprego e do desemprego. Frequentemente relacionados com estratégias de investimento, reestruturações sectoriais, encerramentos e deslocalizações de empresas, as variações na oferta de emprego deixaram de poder ficar restritas aos limites dos quadros de análise de nível regional ou nacional.

Deste modo, o trabalho de investigação desenvolvido no âmbito da dissertação de mestrado "Processos de Reestruturação Industrial e Desemprego - Implicações Geográficas. O Eixo Setúbal-Palmela-Montijo-Alcochete» ${ }^{2}$ pretende obter uma melhor compreensão dos processos actuais de perda de emprego na indústria, assente no exercício da relação que os territórios desempenham em articulação com as opções a adoptar nos processos de reestruturação industrial. Nesta perspectiva, considerámos a possibilidade de os factores geográficos actuarem concatenados com as alterações adoptadas na organização da produção.

Com este objectivo, organizámos o trabalho em quatro capítulos, procurando evoluir, sob o ponto de vista metodológico, do geral para o particular. No primeiro capítulo expusemos diferentes abordagens teóricas da relação entre trabalho e capital no processo de produção e respectivas implicações ao

2 Dissertação de mestrado em Geografia Humana e Planeamento Regional e Local, apresentada à Faculdade de Letras da Universidade de Lisboa, sob orientação da Prof. ${ }^{a}$ Dr. ${ }^{a}$ Maria Lucinda Fonseca, desenvolvida com o apoio do projecto de investigação «DivesT - Desinvestimento e Impactes Económicos, Sociais e Territoriais» (Projecto POCTI/34037/GEO/2000 - FCT). 
nível das diferenças no desenvolvimento regional, assim como as interacções entre os lados da oferta e da procura no mercado de trabalho. No segundo capítulo, foram tratadas distintas configurações da reorganização da produção com efeitos ao nível da alienação de postos de trabalho e respectivos impactes territoriais, tendo sido identificadas três formas principais: intensificação, investimento/mudanças técnicas e tecnológicas e racionalização. O terceiro capítulo procurou interpretar a reestruturação da siderurgia portuguesa à luz do modelo apresentado no capítulo anterior, com a vantagem de se poderem tratar os três processos distintos de reorganização da produção, tantos como os segmentos de produção do Grupo Siderurgia Nacional, com incidência no mesmo sector e implicações ao nível do mesmo espaço geográfico. No quarto capítulo é apresentado o estudo de caso, o qual é dedicado à investigação do comportamento das firmas abrangidas pela Operação Integrada de Desenvolvimento da Península de Setúbal (OID/PS) no eixo Setúbal-Palmela-Montijo-Alcochete, que observaram processos de contracção no emprego, com encerramento total ou parcial, recorrendo para o efeito ao inquérito de uma amostra de empresas.

Concluindo, a intervenção do Estado num quadro de crise, marcado pelo desemprego elevado e salários em atraso, através do lançamento da OID/PS (1989-1993), induziu um processo de revitalização regional e de reestruturação industrial que levou à alteração da especialização produtiva e a uma mutação espacial das principais áreas de desenvolvimento. Importava perceber as reais consequências em termos do emprego nos anos subsequentes e que características assumiu o novo quadro regional do emprego.

De acordo com os interesses determinados pelo perfil do capital que compunha as diferentes empresas, a reorganização da produção foi concretizada pelo recurso aos mecanismos identificados no enfoque teórico do trabalho. De facto, como também se procura demonstrar pelo caso da siderurgia portuguesa, não sendo apenas o contexto territorial que determina a opção por diferentes mecanismos de reorganização da produção, a sua exequibilidade e concretização não deixam de estar condicionadas pelas características do espaço onde se desenrola o processo.

No que concerne ao desemprego, considerado como um dos impactes territoriais das diversas formas de reorganização da produção, apesar de ter diminuído durante a OID/PS, manteve taxas superiores à média nacional e adquiriu uma estrutura característica marcada pela elevada componente do chamado desemprego de longa duração (correspondia a 44\% do desemprego, em Dezembro de 1999, segundo os dados do IEFP). Os desajustamentos que se constataram no mercado de trabalho da Península de Setúbal configuram uma certa incapacidade do território para absorver o grosso da mão-de-obra disponível, mas também de carências de formação escolar e profissional e da desarticulação e mesmo inadequação entre a qualificação profis-sional e a qualificação requerida pelas empresas. 
A esta situação não será estranho o facto de a indústria que cresceu nos concelhos atravessados pela A-12, de Setúbal a Alcochete, reflectir por um lado a existência de um "cacho» montado em torno da Autoeuropa, que ocupa cerca de 7000 postos de trabalho, e, por outro, uma pulverização de pequenas empresas sem um nexo de integração económica e regional entre si, geradoras de pouco emprego, predominantemente no grupo dos trabalhadores «semi e não qualificados», e com uma "taxa de mortalidade» importante.

Finalmente, ao contrário da pretendida diversificação sectorial, a região ficou mais dependente de um sector - o automóvel, e de um grande investimento - o da Autoeuropa. É certo que toda a fileira ligada ao sector automóvel beneficiará da implantação de uma indústria tecnologicamente evoluída e de significativa dimensão na Península de Setúbal. No entanto, os riscos para os níveis regionais de emprego decorrentes de uma mudança de estratégia dos capitais do sector quanto à localização dos investimentos são reais e poderão resultar directamente numa situação de grave crise económica e social na região. Deste modo, os problemas de um determinado território que acolhe grandes investimentos industriais, nomeadamente no que concerne ao mercado de trabalho, parecem não se restringir apenas à questão do nível tecnológico implicado. Normalmente, os padrões tecnológicos são elevados, tendo em conta os rigorosos critérios de competitividade em presença e a necessidade absoluta de obtenção de altos índices de produtividade. Essencialmente, o que se afigura cada vez mais importante é a posição que as estruturas sócio-produtivas regionais conseguem assumir - de maior ou menor dependência relativamente aos processos de decisão - na rede global da produção. 